\title{
SISTEM INFORMASI PENGGAJIAN DAN MONITORING KEHADIRAN PEGAWAI HONORER DAN PNS PADA KANTOR SISTEM ADMINISTRASI MANUNGGAL SATU ATAP (SAMSAT) UNIT PELAKSANAAN TEKNIS DAERAH (UPTD) KABUPATEN BERAU
}

\author{
Ekawati Y. Hidayat $^{1)}$, Kusno Harianto ${ }^{2)}$, Eddy Kurniawan Saputra ${ }^{3)}$ \\ ${ }^{1}$ Manajemen Informatika, STMIK Widya Cipta Dharma \\ ${ }^{2}$ Teknik Informatika,STMIK Widya Cipta Dharma \\ ${ }^{3}$ Sistem Informasi,STMIK Widya Cipta Dharma \\ $1,2,3$ Jl. Prof. M. Yamin No. 25, Samarinda, 75123 \\ E-mail : ekawati_stmik@yahoo.com ${ }^{1)}$, kusnoharianto97.kh@gmail.com ${ }^{2)}$, kurniawaneddy@ rocketmail.com $^{3)}$,
}

\begin{abstract}
ABSTRAK
Penelitian ini dilakukan dalam rangka membangun sistem informasi sistem penggajian pegawai honor dan monitoring kehadiran PNS pada SAMSAT UPTD Kabupaten Berau menggunakan Barcode. Adapun metode pengumpulan data yang dilakukan adalah wawancara, observasi dan studi pustaka. Sedangkan untuk metode pengembangan sistem alat bantu yang digunakan adalah Flow of Documents, Contex Diagram, Data Flow Diagram, HIPO.

Manfaat sistem sistem informasi penggajian pegawai honor dan monitoring kehadiran PNS pada SAMSAT UPTD Kabupaten Berau ini yaitu mempermudah petugas penggajian dalam rangka menghitung gaji pegawai honor serta dapat mendukung kebijakan kantor yaitu penerapan sanksi perubahan suatu proses absensi manual menjadi terkomputerisasi seperti atas keterlambatan serta tidak masuk tanpa keterangan pada SAMSAT UPTD Kabupaten Berau.
\end{abstract}

Kata Kunci: Sistem Informasi, Penggajian Pegawai Honor, Monitoring PNS, Barcode

\section{PENDAHULUAN}

SAMSAT UPTD Kabupaten Berau merupakan instansi milik pemerintahan yang besar dan memiliki PNS dan pegawai honorer yang cukup banyak sehingga dalam kaitannya dengan sistem penggajian pegawai honorer dan monitoring kehadiran PNS diperlukan sebuah sistem informasi yang dapat menjawab berbagai permasalahan yang muncul dalam kegiatan operasionalnya.

Adapun sistem penggajian yang berjalan saat ini pada SAMSAT UPTD Kabupaten Berau didasarkan pada data absensi yang dilakukan secara manual yang mana pegawai menandatangani daftar kehadiran di dalam form yang telah disediakan setiap jam masuk dan jam pulang.

Sistem yang berjalan ini memiliki banyak kelemahan yaitu petugas penggajian harus melakukan perhitungan absensi secara manual dari form absen harian yang ditandatangani oleh pegawai. Selain itu dengan adanya kebijakan sanksi potong gaji untuk tenaga honorer apabila terlambat serta peraturan pemerintah tentang disiplin PNS, beberapa pagawai nakal masih dapat memanipulasi isian jam kehadirannya karena jam kehadiran pada form absensi masih diisi oleh pegawai secara manual.

Dengan dibangunnya Sistem Informasi Penggajian Dan Monitoring Kehadiran Pegawai Honorer dan PNS
Pada Kantor Sistem Administrasi Manunggal Satu Atap (SAMSAT) Unit Pelaksanaan Teknis Daerah (UPTD) Kabupaten Berau, diharapkan dapat mempermudah petugas penggajian dalam rangka menghitung gaji pegawai honor serta dapat mendukung kebijakan kantor yaitu penerapan sanksi perubahan suatu proses absensi manual menjadi terkomputerisasi seperti atas keterlambatan serta tidak masuk tanpa keterangan pada SAMSAT UPTD Kabupaten Berau.

\section{RUANG LINGKUP PENELITIAN}

Dalam penelitian ini permasalahan mencakup:

1. Proses absensi pegawai.

2. Proses perhitungan gaji pegawai honorer.

3. Proses monitoring pelanggaran kedisiplinan PNS. 


\section{BAHAN DAN METODE}

\subsection{Sistem Informasi}

Sistem Informasi adalah sistem informasi mencakup sejumlah komponen (manusia, komputer, teknologi, informasi, produser kerja) ada sesuatu yang diproses (data menjadi informasi) dan dimaksudkan untuk mencapai suatu sasaran (Kadir, 2003).

\subsection{Barcode}

Barcode atau dalam bahasa Indonesia seringkali disebut kode batang adalah an optical machine-readable representation of data. Kode batang garis dab berwarna hitam putih tersebut mengandung satu kumpulan kombinasi yang berlainan ukuran, dan disusun sedemikian rupa menurut aturan tertentu sehingga dapat diterjemahkan oleh mesin pembacanya (Wahtono, 2010).

\subsection{Metode Air Terjun}

Waterfall menggambarkan untuk rekayasa perangkat lunak, yang sering disebut juga dengan "siklus kehidupan klasik". Waterfall mengusulkan sebuah pendekatan kepada perkembangan perangakat lunak yang sistematik dan sekuensial yang dimulai pada tingakat dan kemajuan sistem pada seluruh analisis, desain, kode, pengujian, dan pemeliharaan.(Pressman, 2003).

\section{RANCANGAN SISTEM/APLIKASI}

1. FOD Yang Berjalan.

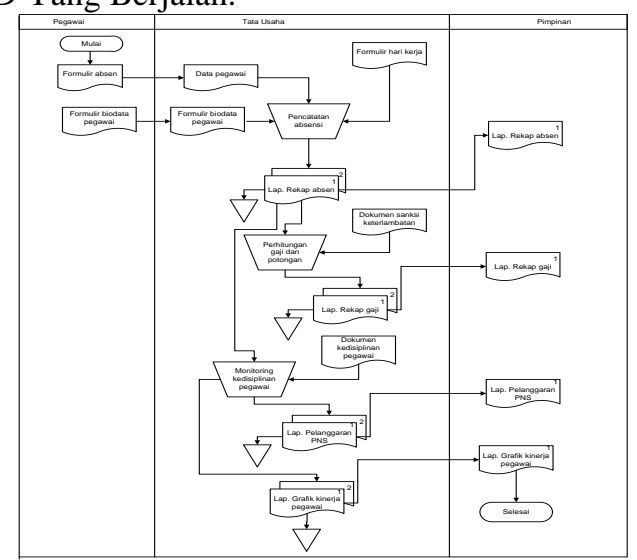

Gambar 1. FOD Yang Berjalan

2. FOD Yang Diusulkan.

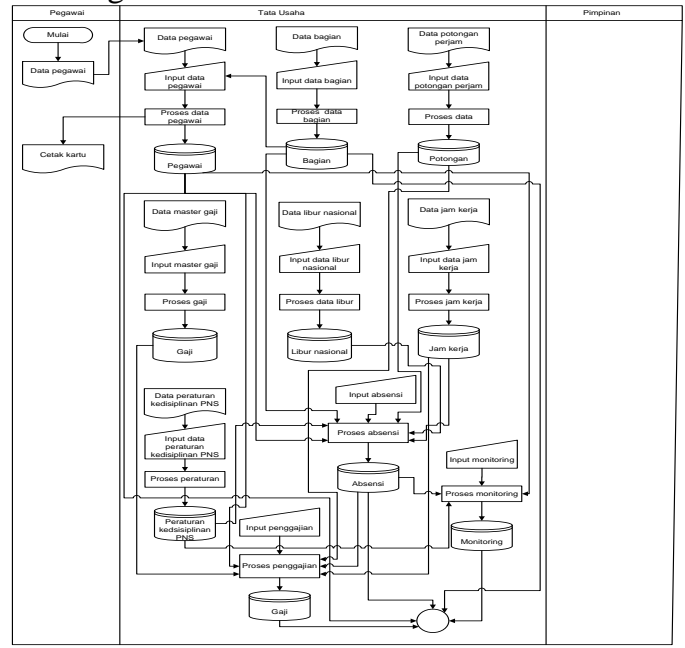

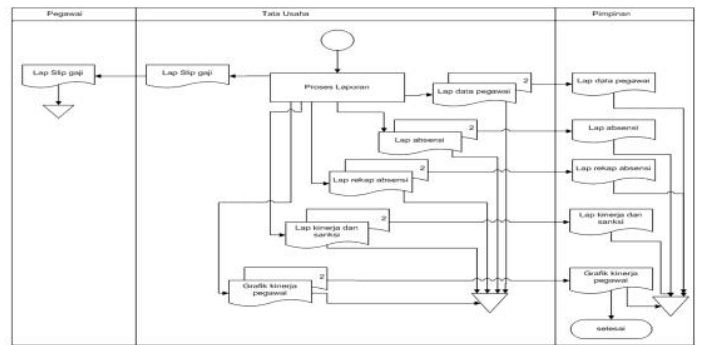

Gambar 2. FOD Yang Diusulkan

3. Contex Diagram.

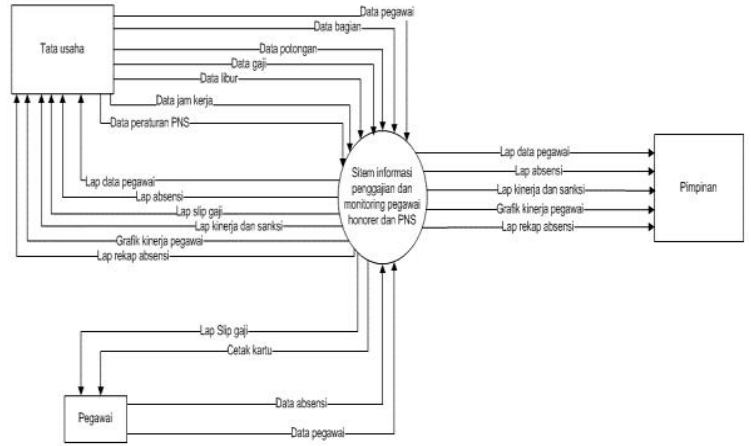

Gambar 3. Contex Diagram

4. DFD Level 0.

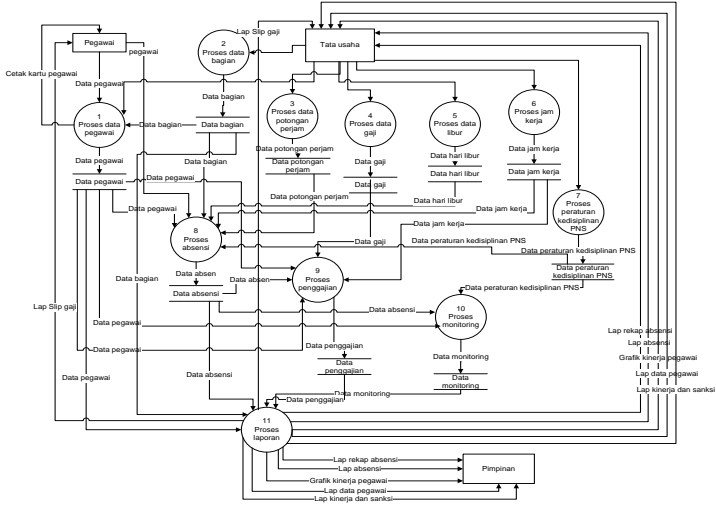

Gambar 4. DFD Level 0

5. DFD Level 1.

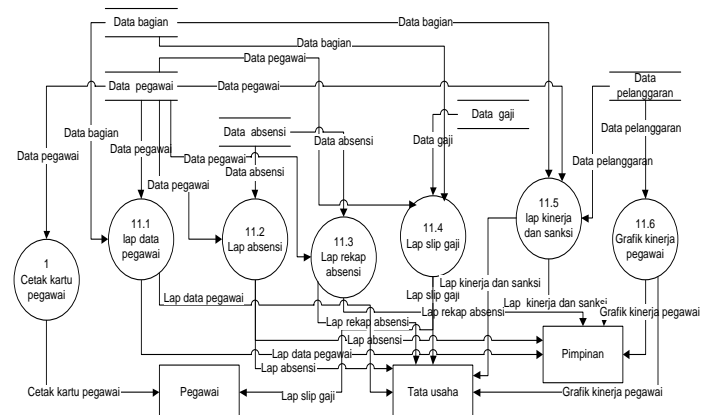

Gambar 5. DFD Level 1

6. HIPO

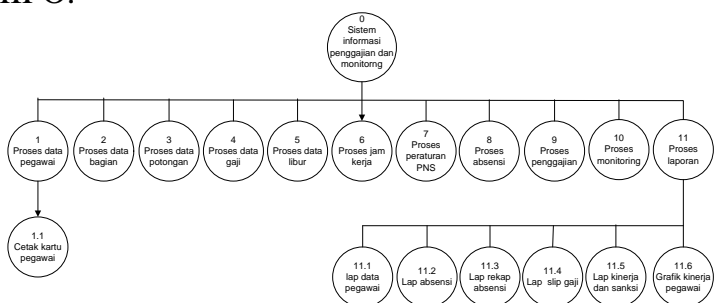

Gambar 6. HIPO 
7. Tabel absensi
NamaTabel
: tb_absensi
FieldKunci : id
Keterangan : Merupakan penampung dari data absensi

Tabel 1. Struktur tabel tb_absensi

\begin{tabular}{|l|l|l|l|}
\hline Nama Field & Tipe & $\begin{array}{l}\text { Panjan } \\
\text { g }\end{array}$ & Keterangan \\
\hline Id & Number & 4 & Id \\
\hline Tanggal & Date/time & 4 & Tanggal \\
\hline NIP & Text & 30 & NIP \\
\hline Jam_masuk & Text & 5 & Jam masuk \\
\hline Jam_pulang & Text & 5 & Jam pulang \\
\hline $\begin{array}{l}\text { Jam_masuk_dia } \\
\text { kui }\end{array}$ & Text & 5 & Jam masuk diakui \\
\hline Jam_plg_diakui & Text & 5 & $\begin{array}{l}\text { Jam pulang } \\
\text { diakui }\end{array}$ \\
\hline Keterangan & Text & 20 & Keterangan \\
\hline
\end{tabular}

8. Tabel perhitungan gaji
NamaTabel
tb_perhitungan_gaji
FieldKunci
: NIP
Keterangan
: Merupakan penampung dari data perhitungan gaji

Tabel 2. Struktur tabel tb_perhitungan_gaji

\begin{tabular}{|l|l|l|l|}
\hline Nama Field & Tipe & $\begin{array}{l}\text { Panjan } \\
\text { g }\end{array}$ & Keterangan \\
\hline Id & Number & 4 & ID \\
\hline NIP & Text & - & NIP \\
\hline Gaji_bulan & Text & - & Gaji bulan \\
\hline Gaji_tahun & Text & - & Gaji tahun \\
\hline Gaji_pokok & Number & 4 & Gaji pokok \\
\hline Hadir & Text & 50 & Hadir \\
\hline Sakit & Text & - & Sakit \\
\hline Izin & Text & - & Izin \\
\hline $\begin{array}{l}\text { Tanpa_keterang } \\
\text { an }\end{array}$ & Text & - & Tanpa keterangan \\
\hline Terlambat & Number & 4 & Terlambat \\
\hline $\begin{array}{l}\text { Potongan_perja } \\
\text { m }\end{array}$ & Number & 4 & Potongan perjam \\
\hline $\begin{array}{l}\text { Potongan_perha } \\
\text { ri }\end{array}$ & Number & 4 & Potongan perhari \\
\hline
\end{tabular}

9. Tabel ijin keluar

NamaTabel

: tb_ijin_keluar

FieldKunci

: id

Keterangan

: Merupakan penampung dari data ijin keluar pegawai

Tabel 3. Struktur tabel tb_ijin_keluar

\begin{tabular}{|l|l|l|l|}
\hline Nama Field & Tipe & $\begin{array}{l}\text { Panjan } \\
\text { g }\end{array}$ & Keterangan \\
\hline Id & $\begin{array}{l}\text { Auto } \\
\text { Number }\end{array}$ & 8 & Id \\
\hline tgl & Date/time & - & Tanggal \\
\hline NIP & Text & - & NIP \\
\hline Pergi_jam & Text & - & Pergi jam \\
\hline Kembali_jam & Text & - & Kembali jam \\
\hline Keterangan_ijin & Text & - & Keterangan ijin \\
\hline
\end{tabular}

5. IMPLEMENTASI

1. Tampilan Form mdi

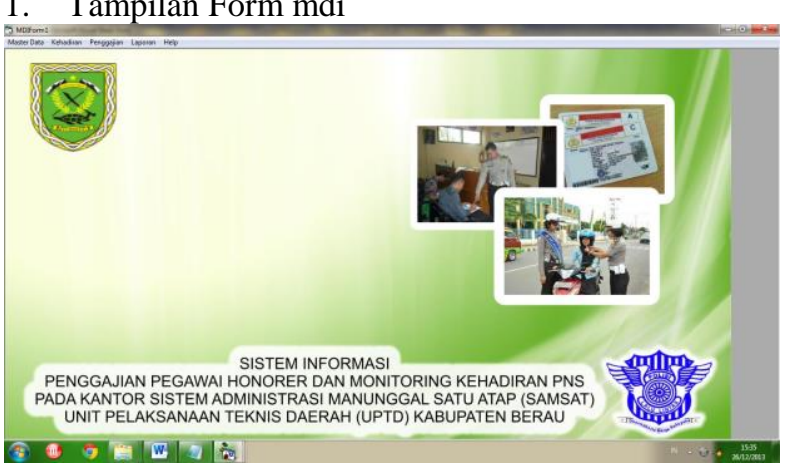

Gambar 7. Form mdi

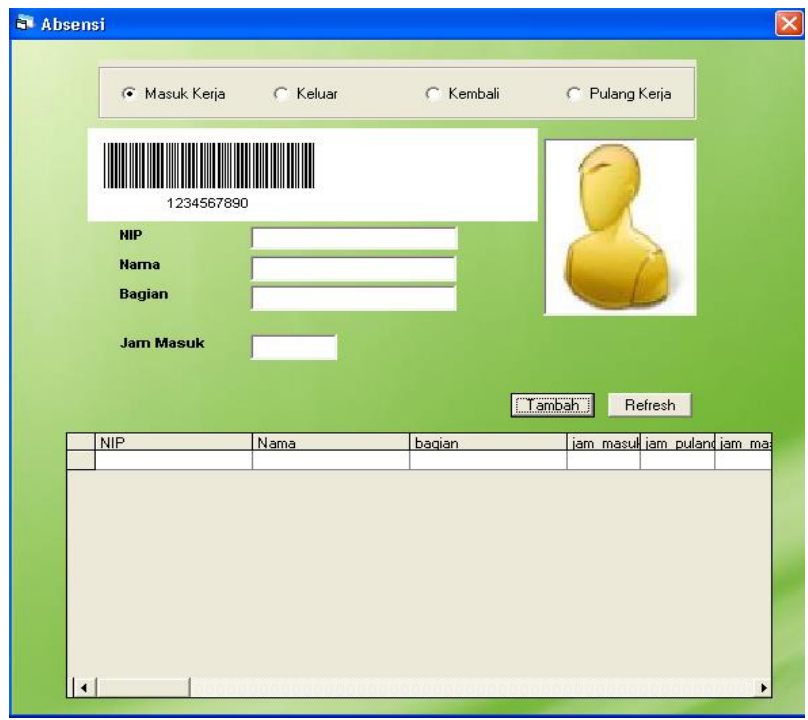

2. Tampilan Form Absensi masuk

Gambar 8. Form Absensi Masuk

3. Tampilan Form Absensi Keluar

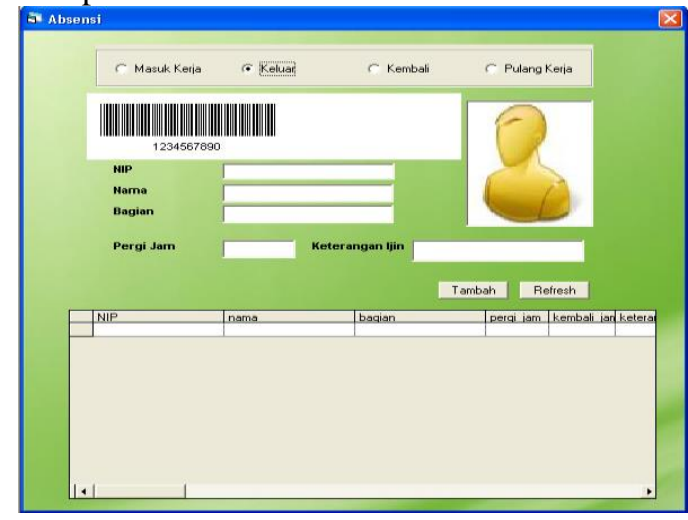

Gambar 9. Form Absensi Keluar 
4. Tampilan Form Absensi Kembali

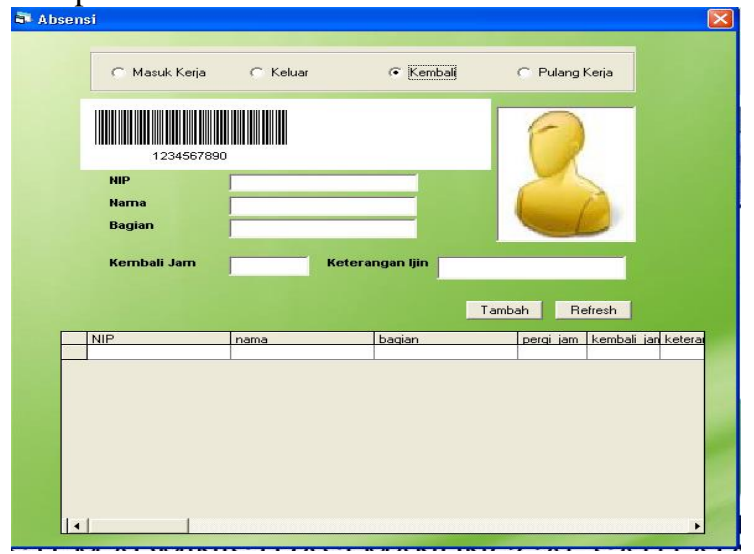

Gambar 10. Form Absensi Kembali

5. Tampilan Form Absensi Pulang

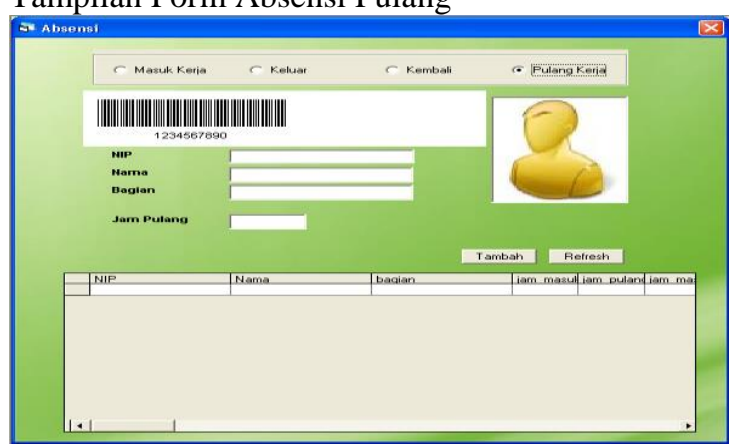

Gambar 11. Form Absensi Pulang

6. Tampilan Form Penggajian

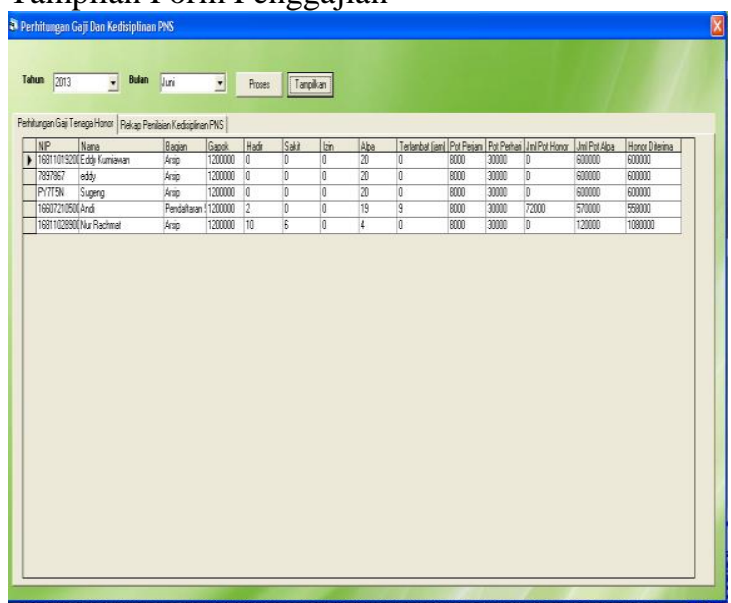

Gambar 12. Form penggajian

7. Tampilan Form Kedisiplinan Pegawai

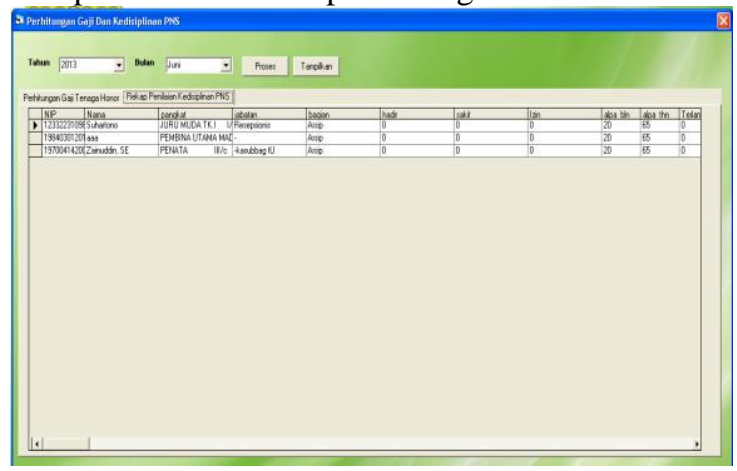

Gambar 13. Form kedisiplinan pegawai
8. Tampilan Laporan Absensi

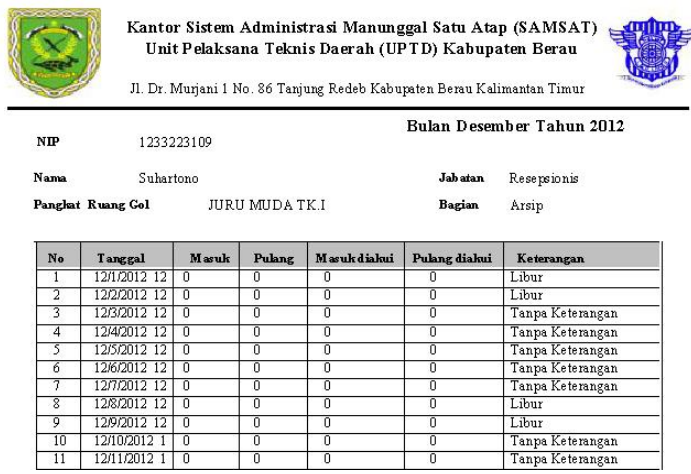

Gambar 14. Laporan Absensi

9. Tampilan Form slip gaji

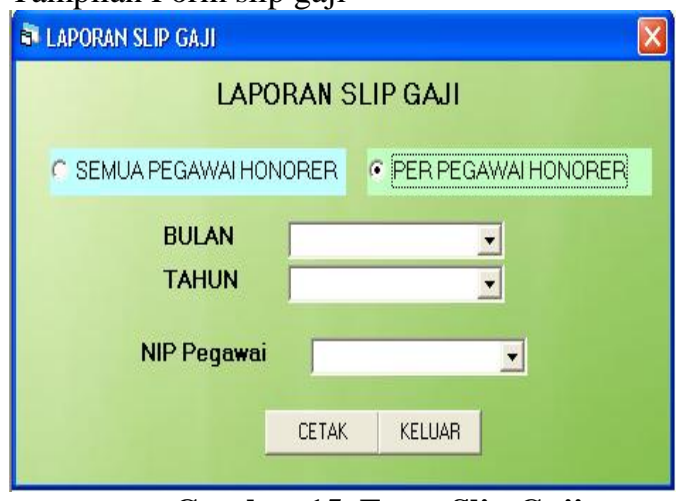

Gambar 15. Form Slip Gaji

10. Tampilan laporan slip gaji

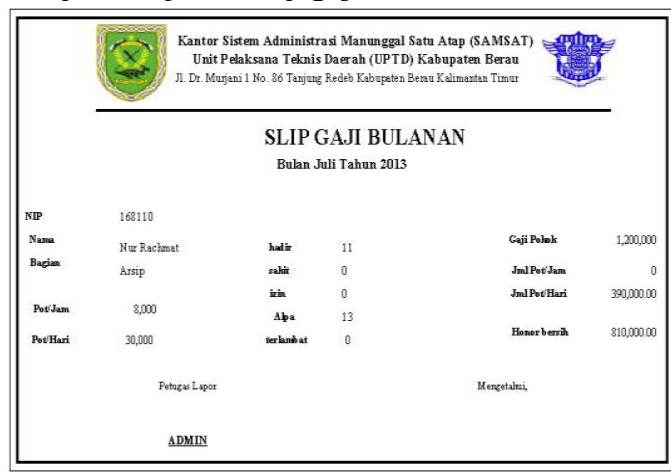

Gambar 16. Laporan Slip Gaji

11. Tampilan Form Grafik Kinerja Pegawai

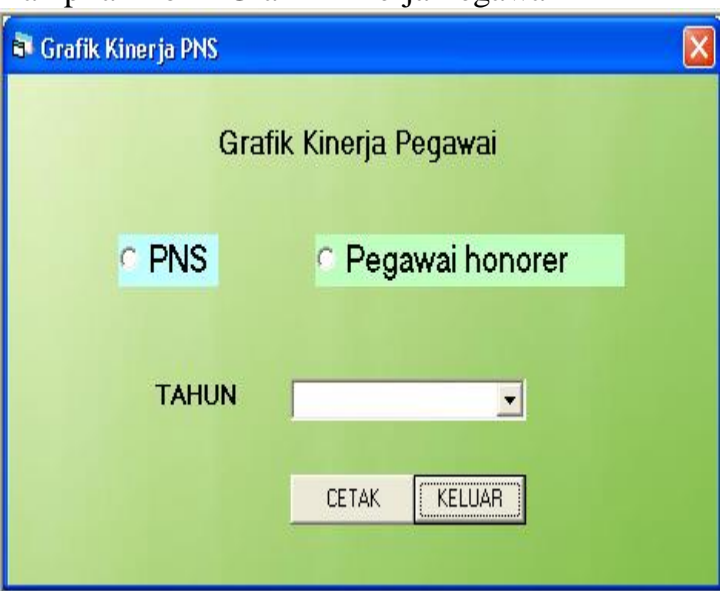

Gambar 17. Form Grafik Kinerja Pegawai 
12. Tampilan Laporan Grafik Kinerja Pegawai

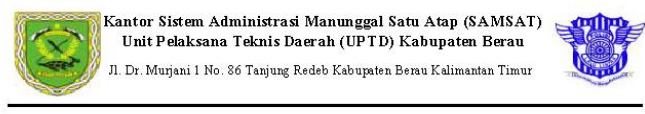

Grafik Absensi Pegawai Honorer Tahun 2013

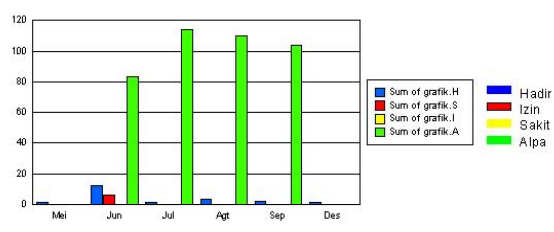

Gambar 18. Laporan Grafik Kinerja Pegawai

\section{KESIMPULAN}

Berdasarkan uraian dan pembahasan, maka penulis dapat mengambil kesimpulan sebagai berikut :

1. Dengan adanya sistem informasi penggajian pegawai honorer dan monitoring kehadiran PNS Kantor SAMSAT UPTD Kabupaten Berau ini, maka dapat membantu administrasi dalam pemrosesan data absen pegawai, penggajian pegawai honorer dan monitoring kehadiran PNS.

2. Dengan penggunaan barcode reader maka tindak kecurangan dalam proses absensi manual dapat diminimalisir.

\section{SARAN}

Berdasarkan dari kesimpulan yang telah di kemukakan di atas dan juga uraian pembahasan pada bab-bab sebelumnya, maka penulis memberikan saransaran yang diharapkan dapat berguna sebagai berikut :

1. Sistem informasi ini dapat dikembangkan menjadi sistem penunjang keputusan dalam rangka pengangkatan tenaga honorer menjadi PNS.

2. Sistem ini dapat dikembangkan menjadi berbasis jaringan apabila jumlah pegawai bertambah banyak seiring dengan pengembangan organisasi UPTD SAMSAT Berau.

\section{DAFTAR PUSTAKA}

Fathansyah, 2004, Sistem Basis Data Lanjut, Bandung : Informatika.

Jack Febrian, 2004, Pengetahuan Komputer dan Teknologi Informasi, Bandung : Informatika

Jogiyanto Hartono, 2003, Analisa dan Sistem Informasi. Pendekatan Teori dan Praktek Aplikasi Bisnis Terstruktur, Yogyakarta: Andi.

Kadir, Abdul, 2003, Pengenalan Sistem Informasi, Yogyakarta : Andi.
Kristanto, Andi, 2003, Perancangan Sistem Informasi dan Aplikasinya, Yogyakarta : Gava Media.

Madcoms, 2005, Pemrograman Tingkat Lanjut dengan Visual Basic 6.0 dan Crystal Report, Madiun : Andi

Pressman. S, 2003, Rekayasa Perangkat Lunak, Yogyakarta: Andi

Sutabri, Tata, 2005. Sistem Informasi Manajemen, Yogyakarta : Andi.

Teguh Wahyono, 2010, Membuat Sendiri Aplikasi dengan Memanfaatkan Barcode, Jakarta : PT. Elex Media Komputindo

Yustisia Pustaka, 2006, Kumpulan Peraturan tentang penerimaan pns, Yogyakarta : Pustaka Yustisia 